\title{
VICTIM-STEREOTYPES OF POSTWAR- EXPELLEES AND THEIR SOCIAL IMPACTS: SOME REMARKS
}

\author{
Geert Franzenburg \\ University of Muenster, Germany \\ E-mail: franzenburg@t-online.de
}

\begin{abstract}
Individual or collective coping with stereotypes - as actors or victims - belongs to human history, and shows different expressions, such as "Black and White" in Africa and America, "Jews", "Sinti and Roma", and "East and West" in Europe; also prejudices concerning generation, sex/gender, and professions belong to this context.

This essay emphasizes, in an exemplary way, on a particular aspect of stereotyping: For Germans, 1945 was (also) the year of flight and expulsion from the East to the West as a kind of master-narrative; filled with stereotypes and myths, this narrative formed their collective memory and identity. Many expellees chose narrations as their strategy to cope with their traumatic experiences. Authors, such as Otfried Preussler, transferred their personal narration into literary forms. There also can be found official documents, such as decrees, which encoded the experiences into neutral information, but, nevertheless, remain traces of human tragedies. Also, modern interpretations of these events show emotional fillings and balance between close and distant style.

The following short evaluation of published documents explains, how people cope with traumatic situations and experiences during a particular historical situation by using stereotypes; by evaluating different kinds of social influence on these stereotypes, the research demonstrates the complexity of stereotypes and the need of contextualization.
\end{abstract}

Key words: contextualization, ego-documents, German expulsion, literature, memory-culture, social influence, stereotypes.

\section{Introduction}

While the (negative) impacts of stereotypes on social life (between partners, groups, ethnic groups, nations) are extensively discussed, there is only few research about the social impacts on stereotypes, particular concerning historical events (Hahn and others, 2008). This research underlines the value of stereotypes as an opportunity to categorize encounters into "we" and "others", and to develop a kind of "product-image"; when keeping unconsidered and used for stereotyping others, they change into prejudices and stigmatisations. Because stereotypes demonstrate how people interpret their experiences emotionally and politically, and how they cope with them at the same time, such research is crucial, particular concerning traumatic events, such as flight and 
OF PSYCHOLOGY IN THE $21^{\text {st }}$ CENTURY Vol. 9, No. 2, 2015

130

expulsion. What people remember from childhood in religious sense, is - even in a secular form - a particular "religious imagination" (Greeley (quoted by Hegy, 2007, 7), such as love, freedom, peace, and acceptance. Although such images seem constructed and experienced (Kunkel and others, 1999, 194 and 198), they represent attitudes, which combine old religious traditions with modern secular needs, particular concerning different social and historical frameworks, such as the German and Czech relationship. Therefore, religious metaphoric language reflects the person's heart religious knowledge in a symbolic and emotional way as a kind of "implicit personal religion" (Argyle, 2000). Such experiences are the main content of religious oriented memories and influence personal life-satisfaction within a dynamic process (Khumalo, 2010, 4-5), and a complex and integrated concept encompassing various facets (Wissing and Temane, 2008). As a dynamic process, memorizing and coping include subjective, social, and psychological dimensions, which lead to self-acceptance, establishment of quality ties to others, a sense of autonomy in thought and action, ability to manage complex environments, ability to suit personal needs and values, pursuit of meaningful goals, and a sense of purpose in life (Ryff, 1989, 1071 and 1074; cf. Khumalo, 2010). Such abilities are crucial, particular in traumatic situations, such as flight and expulsion. Because such effects depend on personal experience, first-hand accounts from expellees facilitate not only an examination of the role of subjectivity in "objective" history, but also provide an opportunity to observe the way, in which collective memory is formed within a group: by sharing individual memories, and forming a common narrative, which often is confronted with alternative, competitive or antagonistic narratives such as between German and Czech people (Assmann and Czaplicka, 1995, Halbwachs, 1950, Hirst, 2008).

\section{Background of Research}

A stereotype can be defined as "a cognitive structure that contains the perceiver's knowledge, beliefs, and expectancies about some human group." (Hamilton and Trolier 1986, 133). It contains schemas about objects, events and people, which help simplifying a complex social environment by quickly and efficiently processing incoming stimuli based on the presence of a few relevant characteristics. Schemas also categorize expectations, once other traits of a category have been encountered by "priming" as giving short information about what features or traits one should expect to encounter. Therefore, a primed concept is more accessible to human consciousness than others, and, thus, can influence how people perceive subsequent information. As a kind of knowledgeand belief-management about social groups, stereotypes are learned through media and everyday interactions with others; nevertheless, there are differences between knowledge of the stereotype and endorsement of it, and between high- and low-prejudiced individuals, because of the different use of controlled cognitive processing to suppress the automatically activated stereotype.

Thus, stereotypes of various social groups can be activated automatically, and they can influence how people interpret incoming information; they also can activate and influence processing, even when people don't endorse them, but people can inhibit these tendencies if they know about them (Lewinston, 1993), and if they have the cognitive capacity to work against them (Blair \& Banaji, 1996). People can try to work around stereotypes, once they have been activated (Devine, 1989).

These general considerations should be exemplified by the stereotypes, which Sudeten-Germans and Czech people developed as their particular coping-strategies. Following und illustrating their own particular interests, their examples remind of the theory of the "ultimate attribution error" (Pettigrew, 1979), which explains the behaviours of "in-groups" and "outgroups" as functions of either "internal" or "external" causes concerning one's inferences about people's behaviours (Power and others, 1996). Positive behaviours will likely be attributed to external causes, when performed by outgroup members and internal causes, when performed by members of the in-group. Thus, the in-group is always held in higher esteem, because good behaviours are seen as internal to the group, whereas bad behaviours are the result of negative external influences.

Such attitudes should be evaluated concerning the expulsions of 1945. These cultural stereotypes - particular of the majority-groups - give highly edited and distorted images of groups that tend to support the way groups are treated in society, can also be demonstrated by Sudeten-Germans 
and Czech people. Germans create the group narrative of the expulsions, while Czech memories of the same period of time present a conflicting story. The interaction of individual memories with

the collective memory of both, the group to which an individual belongs, and groups with differing collective memories, is a key to understand the importance of the expulsions in Central European history since the end of the Second World War. Conflicting and shifting collective memories still govern the relationship between Czechs and Sudeten-Germans to the present day. Furthermore, analysing the collective memories of both, Czechs and the Sudeten-Germans, helps to understand the national and ethnic identities of both groups: Collective memory plays a huge role in uniting the members of a given group, and defines their relationship to the world around them (Assmann and Czaplicka, 1995, Halbwachs, 1950, Hirst, 2008). The collective memories of persecution and victimhood on both sides of the expulsions have defined the identities of Czechs and SudetenGermans for more than sixty years. Political acceptance of the collective narrative of the expulsions has been crucial to the development of a unified identity, both for those who were expelled, and for those who did the expelling. (Agnew, 2004).

\section{Focus of Research}

The evaluation of these narrations should answer the following questions:

1. What social background influenced the experiences of German and Czech people 1945?

2. How did the expellees cope with these impacts?

3. What kind of metaphoric and stereotypes did they use to explain their experiences?

a) religious - secular

b) for persons - things - events

c) considered - not considered

These questions should be answered both way, quantitative and qualitative, in order to evaluate how, and how often specific stereotypes are used in particular situations of expulsion and flight.

\section{Methodology of Research}

\section{General Background of Research}

Personal memories of an event are inherently subjective, as they filter apparently objective facts through a lens of individual beliefs and opinions. Collective memory, on the other hand, as well as collective history, collects many of these unique experiences and perspectives to construct the event in the minds of a group (Hirst, 2008). The individuals involved may have all endured the same traumas and survived the same ordeals, but no two accounts will ever be exactly identical. Since the Sudeten Germans now have no concrete link to their homeland, those collective memories are one of the main ways the group is able to maintain its unity; these memories primary are concerned with desolate food, accommodations in the camps, and with treatment by the Czech nationalists. On the Czech side, the primitive conditions of the barracks for the Germans were a logical consequence of their attitudes during Nazi-era. Thus, individual experience that contradicts the master- narrative of collective memory, does not necessarily prompt an individual to reject this collective memory. It is likely that, on the contrary, the motifs and plots of collective memory in many cases replaced memories of events, through which individuals had actually lived. In many cases, memories of kind Germans or the brutality of their forced resettlement were driven from the minds of the Czech people who had personal experience of the events, because they did not fit it into the officially sanctioned master-narration; thus, they became cultural artefacts or stereotypes.

\section{Instruments and Procedure}

The texts (novel, memoirs, decrees, studies) should be evaluated both ways, using quantitative 
OF PSYCHOLOGY IN THE $21^{\text {st }}$ CENTURY Vol. 9, No. 2, 2015

132

(ANOVA) and qualitative (Grounded Theory) instruments. These should evaluate how social and individual stereotypes influenced attitudes, beliefs, and interpretations of individuals and groups, and how education can draw benefit from such influences and interdependences. Both instruments together build and demonstrate a multidimensional approach, which facilitates an overview and insight concerning stereotypes and their social impacts.

\section{Sample of Research}

Content of the exemplary literature-research are nine published and unpublished autobiographical narrations - memoirs, fiction and decrees - about own experiences of both nations during the End of War 1945, particular flight and expulsion. Because there are different coping strategies - direct or indirect way, real or fictive, cognitive or emotional - there are different kinds of narration that will be evaluated:

1. Otfried Preussler, the flight of the holy family (quotations) as a model, how to encode and decode, de- and reconstruct experiences,

2. memory-narrations of expulses as a way of coping with traumata,

3. comments and interpretations.

Evaluated single and in comparison, the psychological and religious, individual and social dimensions of memory-cultures become obvious, exemplified by the element of stereotypes.

\section{Data Analysis}

The evaluation of Preussler's narration about the flight of the holy family (as quotations), of memory-narrations of expulses and Czech people, and modern comments and interpretations, should demonstrate how the social environment influenced the experiences of both groups and their stereotypes, and how both groups coped with these impacts by using different types of stereotypes. Therefore, these texts will be evaluated also in comparison to each other, concerning the statistical and hermeneutic meaning of particular stereotypes. The material consists only of short examples, which allow some conclusions, but is not representative or a real overview.

Evaluated are the following texts:

1. Preussler, flight (three chapters of the novel as examples):

Start of the refuge (chapter 1) - looking for shelter until morning (chapter 19) - empathy with the victims (chapter 28)

2. Czech quotations (from Turmwald, 1951):

From a female settler (peace-loving neighbourhood and violent soldiers) - From a nurse-nun (a suffering German would get no help because Germans did not help her) - from a new landowner (benefit from the expulsion) - from a camp-officer (Germans have no God) - from the Benes-Decrees (Germans as Fascists without Czech citizenship rights)

3. From German quotations (Turmwald, 1951):

Soldiers attacking the Germans - Germans in camps without luggage received things that were uniformly unusable - Russian officers prevented worse violence - astonishment about Czech violence - German women rescued their husbands from starvation

4. From dissertations

Sudeten-Germans with strong preferences for practical higher secondary schooling (Semrad, 2015) - Czech administration and committees responsible for expulsions (Gerlach, 2007). 
Evaluating the texts with the method of Grounded Theory, the following categories of stereotypes seem to be crucial:

- "Not civilians but troops were the devils"

- "Germans are rightless"

- "The others are the winners"

- "There are friendly helpers/angels"

- „Empathy is a key for understanding“

- „Germans are Nazis“.

Both approaches, quantitative and qualitative, underline the crucial meaning of each of these categories of stereotypes, which are core-elements of the cultural identity of an ethnic group, and, therefore, culturally and socially influenced: Most of the quotes (58\%) emphasize on the stereotype "Germans are Nazis" - German and Czech narrations, Preussler, Benes-Decrees and the Dissertation of Gerlach, each of them from a different point of view and with different purposes. These different approaches underline that this stereotype is social influenced by different group-purposes: While the Czech narrations, and also the Benes decrees emphasize on the collective memory-culture with the focus on the "master-narration" of German occupation and oppression 1938, which transfers the Czechs from actors and collaborators to victims, the Germans found in this "prejudice" a collective excuse for suffering from expulsion and violence. Preussler did not mention Nazism, but emphasizes on the stereotyping of the (German) refugees by the Czech people. Similar Gerlach emphasizes on the "ethnical cleanse" by Czech authorities and administration. Social influences, therefore, primary mean peer-group- and public influence. $42 \%$ of the quotations emphasize on the stereotype "not the civilians but troops were the devils": Preussler (2x), two Czech and two German narrations mention this stereotype. Particular in Preussler's story, this fact is expressed. Also, the other narrations confirm that the violence came from soldiers; this fits to Gerlachs theory that Czech officials were more responsible for the expulsions than others. Social influence in this context means recognition of strong relationships between Germans and Czechs by mixed families, friendship and cooperation.

There also are three pairs of stereotypes, which are complementary:

1. "Germans are Nazis" - "not the civilians but troops were the devils":

2. "Germans are rightless" - "The others are the winners"

3. "There are friendly helpers/angels" - "Empathy is a key for understanding".

The quantitative results (Anova) underline the emphasis on these stereotypes (9 German, 5 Czech quotations):

1) "Germans are Nazis" (57\% yes, D: $M=1,33, \mathrm{D}, 0,5 ; \mathrm{CZ}: \mathrm{M}=2,00,0,00)$

"Troops are devils" 43\% yes D: M=1,1, D, 0,$13 ; \mathrm{CZ}: \mathrm{M}=2,00,0,00)$

2) "Germans are rightless" (29\% yes, D: $M=1,00, D, 0,0 ; C Z: M=1,8,0,45)$

"The others are winners" (36\% yes, D: M=1,0 D, 0,$0 ; \mathrm{CZ}: \mathrm{M}=2,00,0,00)$

3) "There are angels" ( $43 \%$ yes, $\mathrm{D}: \mathrm{M}=1,1, \mathrm{D}, 0,33 ; \mathrm{CZ}: \mathrm{M}=2,00,0,00)$ "Empathy is the key" (28\% yes, D: M=1,00, D, 0,$0 ; \mathrm{CZ}: \mathrm{M}=1,8,0,45)$ -

Concerning the political atmosphere (Nazi-past) as the core-impact on the experiences of German and Czech people 1945, the research evaluated different coping-approaches (German, Czech), illustrated by different metaphoric and stereotypes. These stereotypes are divided into sub-stereotypes, which are partly religious encoded (angel, devil, holy child, holy land) and have to be secular decoded (helpers, responsibility, destination); they concern persons (soldiers, men, women, police), things (luggage, house, room, food) and events (camp, warning, way); some seem to be considered and conscious (help, rescue, hate), some unconsidered or unconscious (Nazi, enemy, winner-looser). 


\section{Discussion}

The results underline the given definition of stereotype as "a cognitive structure that contains the perceiver's knowledge, beliefs, and expectancies about some human group" (Hamilton and Trolier,1986, 133): Evaluating the situation of the Sudeten-German expellees 1945 from a socialpsychological point of view, combined with a multidimensional approach (including historical, educational and theological, quantitative and qualitative aspects), and with different kinds of narrations and documents (fiction, autobiography) demonstrates that these victim-stereotypes as parts of a master-narrative are constructed in a complex way, combining knowledge, beliefs, and expectancies about oneself, the peer-group, and the others. Thus, they transfer the social influence from political and social background into self-definition, cultural identity, and memory-culture of both groups, Sudeten-Germans and Czech people. The research also evaluated their different sources: Stereotypes, which are part of collective memory (-culture), such as the German doublerole as actors and victims of oppression. Stereotypes, which depend more on individual and group experiences, such as Germans as rightless - Czechs as winners, and are, therefore, group-oriented and complementary, although mentioned by both, German and Czech witnesses. Although most of the stereotypes confirm - analogue, and like an answer to the Czech "master-narration" of their own oppression by the Germans - the German self-image as victims of oppression and expulsion, there can also be found positive oriented stereotypes, which, however seem to depend mostly on individual experiences ("There are friendly helpers/angels - Empathy is a key for understanding").

The least important stereotype concerns the role of culture and education, and seems more of academic or research interest. The story of the flight of the holy family to Egypt (Preussler) emphasizes on the religious aspect of such stereotypes, which also are implicit in the other ones:

When most of the quotations (57\%) - German and Czech - emphasize on the double- victim stereotype "Germans are Nazis" from different perspectives and with different purposes, Germans and Czechs are both part of the religious oriented common and global "master-narrative" of "guilt and punishment", and of the comparison between situations 1938 and 1945 which is often quoted by Czech people. Therefore, such stereotypes depend on their particular context. In this context, also metaphoric is used, such as the German term "Pack" (Preussler), the illustration of "white armbands" and other Nazi/SS-signs (German)) or the blaming of collaboration (Czech). That almost half of the quotations (43\%) - German and Czech ones - blame soldiers and troops (or police officers) instead of civilians for violent aggressions, can be read as a confirmation of the strong relationships between German and Czech families or neighbourhoods.

While this particular "Nazi"-stereotype overcomes ethnic barriers because of its ambivalence, the stereotype "Germans are rightless" is quoted only by $29 \%$ of the quotations, because it only emphasizes a single (German) victim narration, but indirectly confirmed by Czech quotes and underlined by metaphoric, such as "like a little child" (Preussler) - "only a few things" "no and unusable baggage" (German) "do not pontificate him" - "Germans have no God" - "they have no citizenship" (Benes) (Czech). A similar complementary stereotype "the others are the winners" (36\%) is part of this victim-narrative and illustrated by appropriate metaphoric: the new owners get all - live in an honest house - came with empty bags, get full ones. That almost half of the quotations (43\%) agree that "there are angels" - as Preussler symbolized it by the arch-angel Gabriel hidden in the donkey - underlines the complexity of the "victim-narration" and its illustrating stereotypes, which show that Germans (women, farmer), Czech people (house-owner police-officer neighbours), and also Russian officers could become such "angels". Part of this complexity is also the emphasis on education, culture, and empathy. Therefore, the question of cause, guilt and punishment remains in the focus of both core-narrations, Czech and German as a mutual challenge (Zich, 1998).

From a religious oriented social-psychological point of view, these observations underline the contextual and social character of collective attitudes. The dualistic and mutual character of these stereotypes (winner - looser, aggressor - victim) facilitates, on one side, national and cultural identity; on the other side, it hinders encounter and coexistence by shifting barriers between majority- and minority-members. Therefore, evaluating such narrations and stereotypes facilitates developing coping-strategies by emphasizing on contact, encounter, and communication. 
Remembering conflicting or competitive national mythologies facilitates understanding, empathy, and prevents from concepts of collective guilt in any form (Glassheim, 2000). Thus, intriguing German and Czech nationalistic aphorisms become obsolete by emphasizing on the value of language and culture. Instead of a mythical idolization of the native language and culture, they become a medium for encounter, as the first Czech president Masaryk underlined: "The nation is not detached from humanity, it is part of humanity to which we all belong," (Hauner, 1991, 18-19).

\section{Conclusions}

According to the "boundary maintenance mechanism" (Barth, 1969), ethnic groups, although mixed together by interactions, neighbourhood, matrimonies, relationships like Germans and Czech people, try to maintain their internal cohesiveness by an "invisible barrier". The results of this research confirm that stereotype might act as such barrier.

Normally, people define themselves and their identities on the base of two main factors: membership of groups and one's own experience. By memorizing and considering their experiences, they understand who they are and can recognize their own place in social systems with reference to past actions. Thus, memory seems crucial in the cultural life of a human being and of an ethnic group. It enables constructing identities on the basis of individual and collective experiences, and maintains a symbolic continuity of past, present, and future. Therefore, it has become a subject of political interest, which uses memory-narrations to popularize preferred attitudes, values, and authority. Such political context facilitates new opportunities for research about the interdependencies of memory, narration, and political action concerning a person's identity and his/her features, which may be transformed into a stereotype, but will not be automatically constructed and commonly shared.

\section{References}

Agnew, H. (2004). The Czechs and the Lands of the Bohemian Crown. Stanford.

Argyle, M. (2000). Psychology and religion: An introduction. London.

Assmann, J., Czaplicka, J. (1995). Collective memory and cultural identity. New German Critique, 65, 125-133.

Barth, F. (1969). Ethnic groups and boundaries. Boston.

Blair, I. V., \& Banaji, M. R. (1996). Automatic and controlled processes in stereotyping priming. Journal of Personality and Social Psychology, 70 (6), 1142-1163.

Devine, P. G. (1989). Stereotypes and prejudice: Their automatic and controlled components. Journal of Personality and Social Psychology, 56, 5-18.

Gerlach, D. (2007). For nation and gain: Economy, ethnicity and politics in the Czech borderlands, $1945-$ 1948. Doctoral Dissertation, University of Pittsburgh.

Glassheim, E. (2000). National mythologies and ethnic cleansing: The expulsion of Czechoslovak Germans in 1945. Central European History, 33, (4), 463-486.

Hahn, Hans-Henning, at all. (Hgs.) (2008). Mythen und Stereotypen in Europa. Breslau.

Halbwachs, M. (1950). On collective memory. New York.

Hamilton, D. L., \& Trolier, T. K. (1986). Stereotypes and stereotyping: An overview of the cognitive approach. In: J. F. Dovidio \& S. L. Gaertner (Eds.), Prejudice, discrimination, and racism. New York, 127-163.

Hauner, M. (1991). Czechs and Germans: Yesterday and today. Washington, Woodrow Wilson International Center for Scholars (East European Studies; No. 30).

Hegy, P. (Ed.) (2007). What do we imagine God to be? The function of "God Images" in our lives. Lewinston.

Hirst, W., Maniert, D. (2008). Towards a psychology of collective memory. Memory, 16 (3), 183-200.

Khumalo, Itumeleng P. (2010). The evaluation of the General Psychological Well-being and the Mental Health Continuum Models in an African context. Potchefstroom (ZA). 
OF PSYCHOLOGY

IN THE $21^{\text {st }}$ CENTURY

Vol. 9, No. 2, 2015

136

Kunkel, M. A., Cook, S., Meshel, D. S., Daughtry, D., \& Hauenstein, A. (1999). God images: A concept map. Journal for the Scientific Study of Religion, 38 (2), 193-202.

Lewinston, M. M. (1993). Self-regulation of prejudiced responses: Implications for progress in prejudice reduction efforts. Journal of Personality and Social Psychology, 65, 469-485.

Pettigrew, T. F. (1979). The ultimate attribution error: Extending Allport's cognitive analysis of prejudice. Personality and Social Psychology Bulletin, 5 (4), 461-476.

Power, J. G., Murphy, S. T., \& Coover, G. (1996). Priming prejudice: How stereotypes and counter stereotypes influence attribution or responsibility and credibility among ingroups and outgroups. Human Сотmunication Research, 23, 36-58.

Ryff, C. D. (1989). Happiness is everything, or is it? Explorations on the meaning of psychological wellbeing. Journal of Personality and Social Psychology, 57, 1069-1081.

Semrad, A. (2015). Immigration and educational spillovers: Evidence from Sudeten German expellees in postwar Bavaria. München.

Turmwald, W. (1951). Dokumente zur Austreibung der Sudetendeutschen. Überlebende kommen zu Wort (AG der Vertretung Sudetendeutscher Interessen).

Wissing, M. P., \& Temane, Q. M. (2008). The structure of psychological wellbeing in cultural context: Towards a hierarchical model of psychological health. Journal of Psychology in Africa, 18 (1), 45-56.

Zich, F. (1998). Germany and the Germans in the attitudes of the people living on the Czech-German border. Czech Sociological Review, 6 (2), 241-59.

Advised by Guna Svence,

Riga Teacher Training and Educational Management Academy, Latvia 